\title{
TITLE:
}

\section{DEVELOPMENTAL ASPECTS OF STROBILATION IN AURELIA AURITA}

$\operatorname{AUTHOR}(\mathrm{S}):$

Kato, Ken-ichi; Aochi, Masatoshi; Ozato, Kenjiro

\section{CITATION:}

Kato, Ken-ichi ...[et al]. DEVELOPMENTAL ASPECTS OF STROBILATION IN AURELIA AURITA. PUBLICATIONS OF THE SETO MARINE BIOLOGICAL LABORATORY 1973, 20: 179-194

ISSUE DATE:

1973-12-19

URL:

http://hdl.handle.net/2433/175778

RIGHT: 


\title{
DEVELOPMENTAL ASPECTS OF STROBILATION IN AURELIA AURITA
}

\author{
KeN-ICHI KATO and Masatoshi AOCHI \\ Department of Biology, Osaka Kyoiku University \\ and \\ KeNJiRo OZATO \\ Department of Biology, Yoshida College, University of Kyoto
}

With 12 Text-figures

Strolibation in Scyphozoa has been well known as a process to produce ephyrae. This process might include the basic aspect to understand the mechanism of cellular differentiation and transformation for the particular pattern of metamorphosis. We believe that the strobilation therefore seems to provide a unique opportunity for the study of growth and development, which has been pointed out by SPANGENBERG (1965). Although some known enviromental factors such as the lighting condition and the low temperature could initiate the strobilation (cf. recent review, SPANGENBERG, 1968), we know little about the possible change which may occur in either the substantial or cellular level during the strobilation and the further metamorphic process. In this report, we are going to describe the morphological and physiological aspects of strobilation in Aurelia aurita.

\section{Strobilation Process}

Material: Polyps of Aurelia aurita used in this study have been obtained from the Department of Biology, Tokyo Metropolitan University. This material had been maintained for several years under laboratory condition using natural sea water. In our laboratory, these polyps have been kept in artificial sea water, Jamarin (manufactured by Jamarin Laboratory, Osaka, Japan) at a temperature range from $20^{\circ}$ to $23^{\circ} \mathrm{C}$ for 3 years. They were fed twice a week with newly hatched Artemia salina. Temperature is a serious morphogenetic parameter. For instance, lowering the temperature could cause the initiation of strobilation in marine schyphystome (KAKINUMA, 1962; SpANGENBERG, 1968). In order to yield many strobilae of Aurelia aurita, the polyps which were originally derived from a single polyp by budding were transferred into the artificial sea water, Jamarin (this will be abbreviated as ASW in the following description) at $15^{\circ} \mathrm{C}$ and maintained until the ephyrae were liberated from the mother polyp. During the present observation, we found that the percentage of strobilation 
initiation and the number of segments in strobilating polyps were markedly varied depending on both the original stage and size of the polyps. Thus, we used exclusively such polyps whose heights (from peduncle to a level just below tentacles) were distributed within $2.0-2.2 \mathrm{~mm}$ range when they were in relaxation state.

Morphological Survey of Strobilation Process: In the developmental studies, morphological details of the strobilation during the process of development can be illustrated as in Fig. 1. This process can be sub-divided into six sequential stages according to the following characteristics.
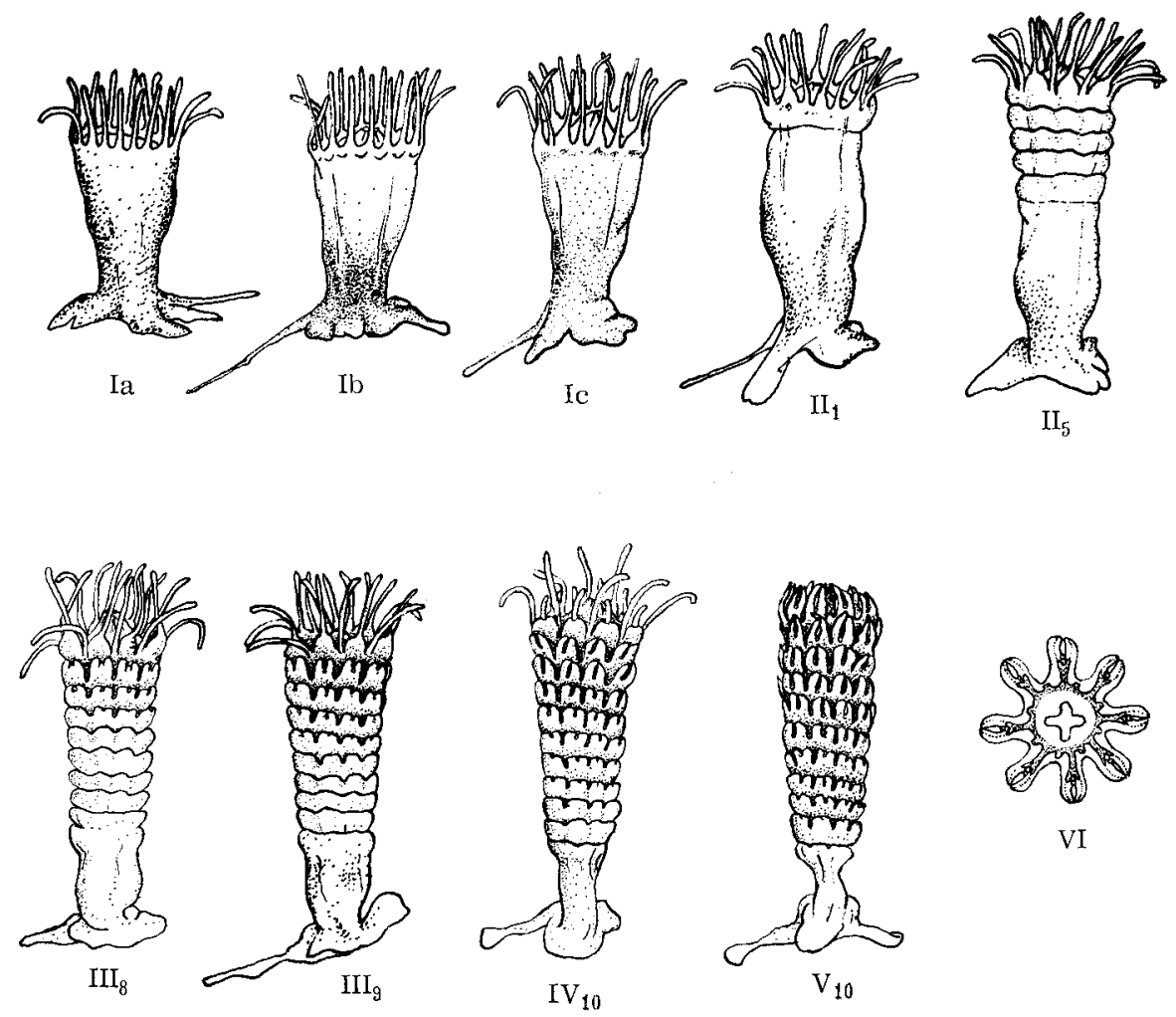

Fig. 1. Strobilation process of Aurelia aurita.

Stage I is the polyps which do not develop any transverse furrow. However, they will begin to elongate distoproximally within a few days, decreasing their width after the successive transfer to the ASW at a lower temperature. At this time, we usually recognized the following morphological changes: (1) the orange colored pigmentation which is commonly observed in the distal part of polyps begins to lose the original diffused distribution and start to concentrate at the proximal part, (2) the marginal region just below the tentacles starts to swell gradually and (3) the internal septa become more clear and detectable such as the surface ridge. Usually this state 
will continue for the following several days (stage Ib). Then, swelling occurs at the bases of each alternate tentacles accompanying with a little accumulation of orange colored pigments. The pigmentation turns to a more dispersed state, and as a result the orange color will distribute evenly from the proximal to the distal part (stage Ic).

Stage II is the polyp at the stage of beginning segmentation. The segmentaion proceeds from the distal end to the proximal part. Each number appearing on the right side of the stage number corresponds to the number of segments. In association with the progress of segmentation, the upper ridge of each segment gradually transforms into eight lobes, except the first segment, which has tentacles. Later, each lobe bifurcates at the middle site where a rhopalium will be formed. This morphogenesis starts from the second segment and continue to the proximal direction one by one.

Stage III represents the process of bifurcation and rhopalium formation in the strobila. Stage IV indicates the following process of the absorption or degeneration of the original tentacles. The first sign of the absorption usually occurs in alternate tentacles, and the resulting eight bases of the absorbed tentacles will later correspond to the sites of the rhopalium.

Stage V is the completion of the tentacle absorption, while Stage VI is the libertation of newly formed ephyrae.

The strobilation process of 278 polyps was examined for about 24 days. Table 1 shows the frequency distibution of organisms at different stages during the incubation at $15^{\circ} \mathrm{C}$. In addition, the body length (height) and the width (measured at the level just below the tentacles) were examined, during and after segmentation. The marked

Table 1. Frequency distribution of the polyps at different stages of strobilation during 24 days of incubation at $15^{\circ} \mathrm{C}$

\begin{tabular}{|c|c|c|c|c|c|c|c|c|c|c|}
\hline \multirow{2}{*}{ Stages } & \multirow[b]{2}{*}{1} & \multirow[b]{2}{*}{3} & \multirow[b]{2}{*}{6} & \multicolumn{5}{|c|}{ Time in Days of Incubation at $15^{\circ} \mathrm{C}$} & \multirow[b]{2}{*}{22} & \multirow[b]{2}{*}{24} \\
\hline & & & & 9 & 10 & 11 & 14 & $17-18$ & & \\
\hline Ia & 100 & & & & & & & & & \\
\hline Ib & & 100 & 8 & & & & & & & \\
\hline Ic & & & 92 & 64.8 & 46.8 & 11.9 & & & & \\
\hline$\overline{\mathrm{II}_{1}}$ & & & & 32.4 & 35.2 & 18 & 2.5 & & & \\
\hline $\mathrm{II}_{2-3}$ & & & & 2.8 & 16.9 & 33.1 & 5.8 & & & \\
\hline $\mathrm{II}_{4-5}$ & & & & & 1.1 & 28.7 & 12.6 & 0.4 & & \\
\hline$\Upsilon_{6-10}$ & & & & & & 8.3 & 6.8 & 1.1 & & \\
\hline$\overline{I I I}_{4-5}$ & & & & & & & 5.1 & & & \\
\hline $\mathrm{III}_{6-10}$ & & & & & & & 54.9 & 10.7 & & \\
\hline $\mathrm{III}_{11-15}$ & & & & & & & 12.3 & 14.5 & & \\
\hline $\mathrm{IV}_{8-10}$ & & & & & & & & 9.7 & & \\
\hline $\mathrm{IV}_{11-15}$ & & & & & & & & 7.2 & & \\
\hline $\mathrm{V}_{8-10}$ & & & & & & & & 8.6 & 50.7 & \\
\hline$V_{11-15}$ & & & & & & & & 47.8 & 49.3 & \\
\hline VI & & & & & & & & & & 100 \\
\hline
\end{tabular}




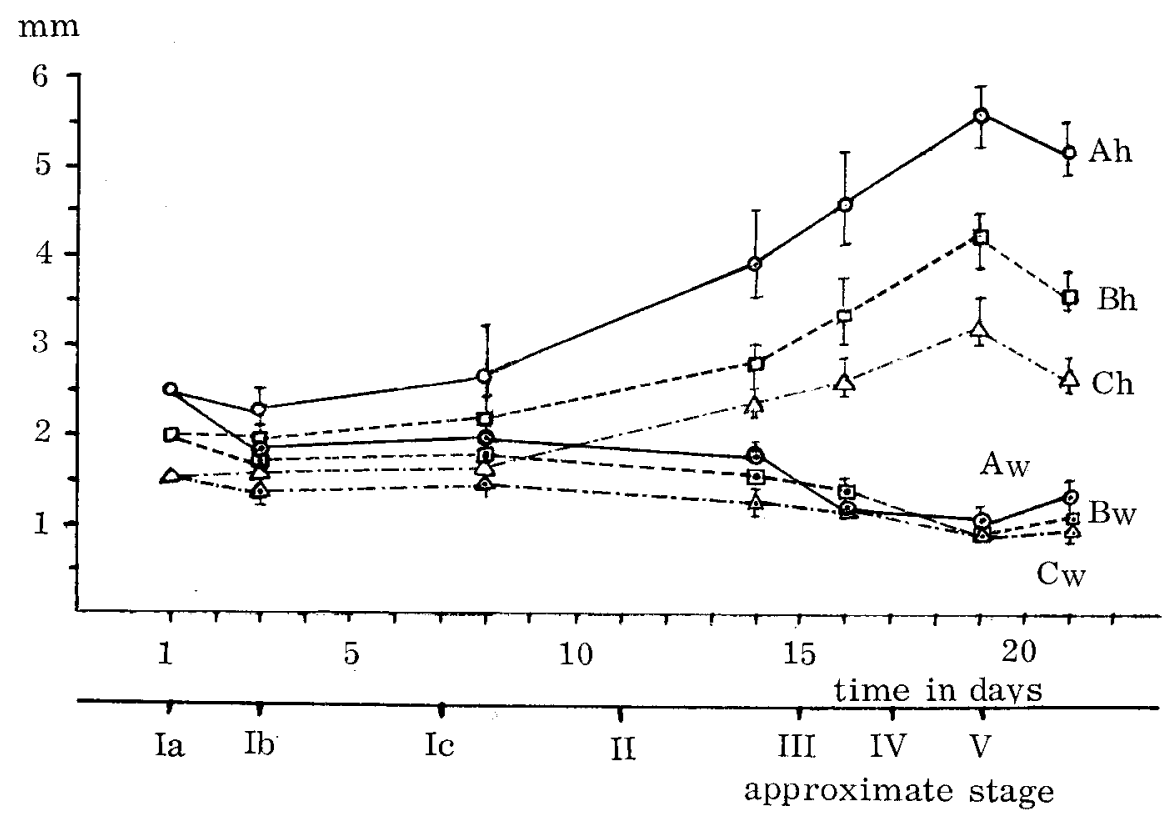

Fig. 2. The average change in body height and width of strobilating polyps followed in three different groups, A, B and C. h or w means height or width, respectively. In group A, 20 polyps which had $2.5 \mathrm{~mm}$ height and width were employed for measurement. Fifteen polyps were examined in groups B and C. Their height and width were $2 \mathrm{~mm}$ in group B and 1.5 $\mathrm{mm}$ in group $\mathrm{C}$.

increase of the body length can be seen from Stage II to Stage V, while the slight reduction of the body width occurred during the morphogenesis (Fig. 2). It is interesting to note that the increase of the body length (height) always accompanies the decrease of the width of the distal part. However, the width of the proximal part may not necessarily decrease in size, and may compensate the even volume distribution for future ephyrae, because each individual ephyra liberated from the distal part always demonstrated the same body size compared with the ephyrae derived from the proximal part. The reduction of the body length at Stage $V$ can be explained as the result of the flattening of each matured ephyra.

\section{Incorporation of Radioactive Precursors}

To understand the physiological base of the successive strobilation, the incorporation of radioactive precursors by polyps and strobilae at different stages has been examined. The organisms were incubated in ASW, and ${ }^{3} \mathrm{H}$-thymidine, ${ }^{3} \mathrm{H}$-uridine or ${ }^{3} \mathrm{H}$-leucine was applied independently. The dose of two radioactive nucleotides was $20 \mu \mathrm{C} / \mathrm{ml}$ and $5 \mu \mathrm{C} / \mathrm{ml}$ in the ${ }^{3} \mathrm{H}$-leucine. Flash labelling technique $(1 \mathrm{hr}, 2 \mathrm{hr}$ and $4 \mathrm{hr}$ ) was used in the present work. Immediately after the completion of the 
flash labelling, the organisms were fixed with $10 \%$ neutral formalin at ice cold temperature, and sectioned following with the standard histological technique. Sakura $\mathrm{MR}-\mathrm{M}_{2}$ was chosed for the dipping emulsion.
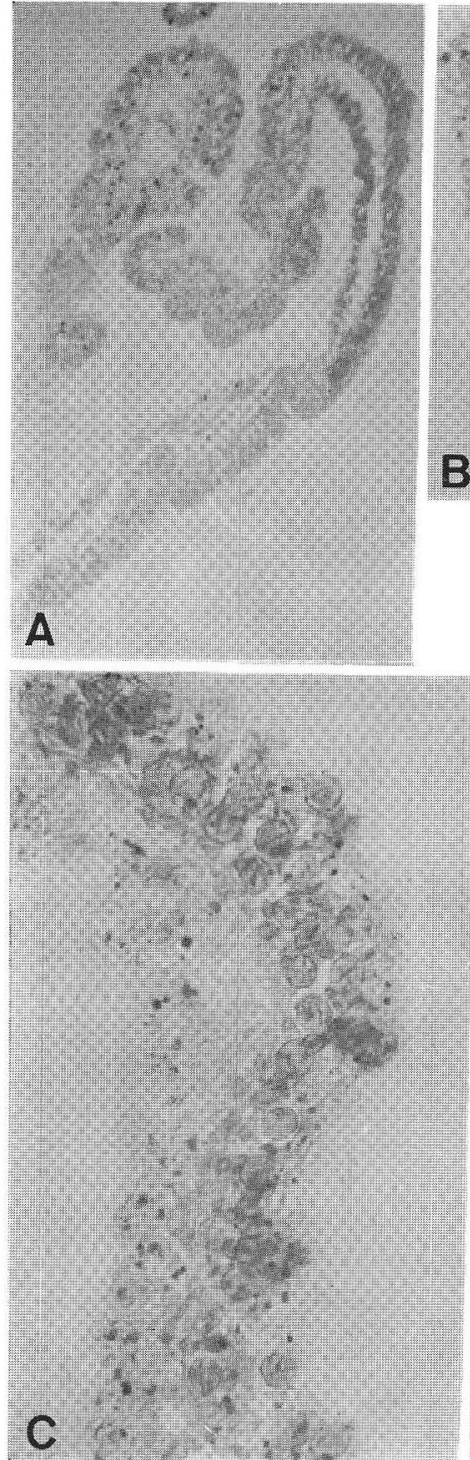
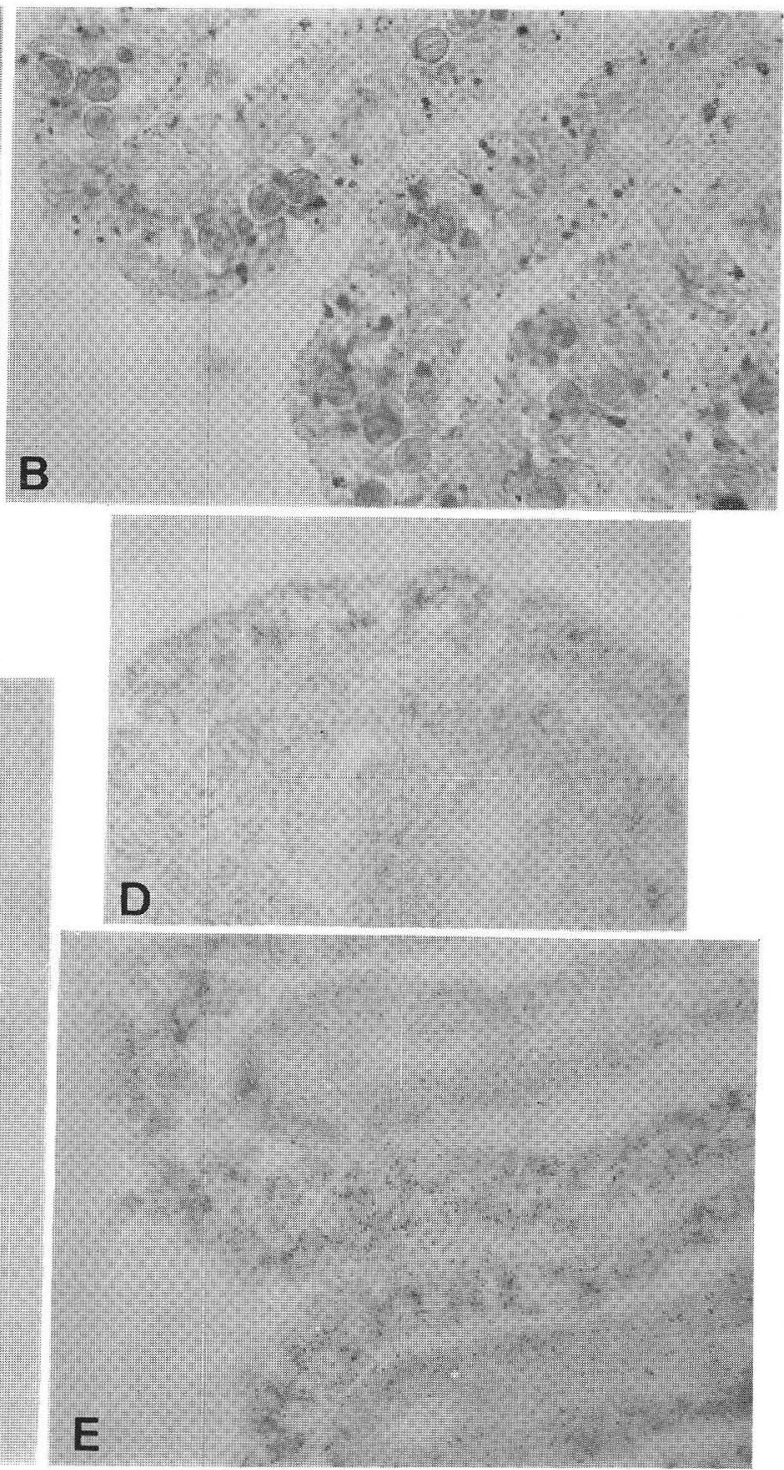

Fig. 3. Autoradiographs showing the incorporation of radioactive precursors.

A: Thymidine uptake in the distal half of a polyp at stage Ia. B: Thymidine uptake in the middle segments of a strobila at stage $\mathrm{III}_{7}$. C: Uridine uptake in the proximal part of an early strobila at stage $\mathrm{II}_{1}$. D: Leucine uptake in the gastric region of a polyp at stage Ia. E: Leucine incorporation in the middle segments of a strobila at stage $\mathrm{III}_{7}$. All the autoradiographs were prepared after the 2-hrs flash labelling at a dose described in the text (p. 182). 
Although hydra has been thought to be impermeable to most exogenous free compounds (BURNETT, BAIRD and DIEHL, 1962), the present results indicated that all three radioactive precursors could be incorporated into the cells. Details of this and other results obtained from pulse labelling will be published later. Pattern analysis strongly suggests that the incorporation of the radioactive material is dependent on the stage of the morphogenesis. The axial distribution of DNA, RNA and protein has been confirmed and reported in two other hydroid species (Li and LENHOFF, 1961; TARDENT, 1963). The high rate of incorporation at the distal part is found in Aurelia, regardless of the difference of tracer employed, even though some differences exist depending on the type of tissue. Thymidine and uridine could easily be incorporated into the ectoderm but not into the endoderm at the polyp stage. However, endoderm becomes more permeable than before, especially in the strobila (B and C in Fig. 3). The incorporation of these tracers continued until the completion of ephyra, although the rate decreased gradually.

However, leucine behaved differently. Leucine uptake is found in both the ectoand endoderm at the polyp stage (D in Fig. 3). At the strobilation stage, ectoderm tends to show a somewhat decreased incorporation of tracer (E in Fig. 3) during the early stage of strobilation, and resume activity at a later stage. Based on the results described above, it is possible to conclude that the level of nucleic acids and protein synthesis in both ectoderm and endoderm are different and fluctuate during the process of strobilation following the built-in programme.

\section{Mutual Relationship between Ectoderm and Endoderm in Strobilation}

SPANGENBERG (1965) examined the subsequent development of the segment separated from the strobilae which already had three segment, and he reported that the distal segment could develop into ephyra. We found that the segment obtained from the strobilae at different stages, namely Stage $\mathrm{II}_{1}$ and $\mathrm{Stage} \mathrm{II}_{5}$ showed subsequent development but reached a different developmental state depending on the experimental condition. For example, ephyra formation from the operated segment not only depends on the developmental stage but also the size of the segment (KATo, AochI and SAKaguchi, 1973). The endoderm holds some regulational mechanism in the process of strobilation. When the strobilae at stage II were cut transversely at the site of the first furrow, the distal part showed some difficulties to develop into ephyrae (5 out of 15 cases and 10 remained as polyp), but almost of all of the unsegmented proximal part would continue further segmentation towards the direction of ephyra formation (14 out of 15 cases, Fig. 4). From this we can consider that the developmental programme has more or less been established when the first segment appeared in the strobila. It was found, however, that if most of endoderm are removed mechanically from either the isolated segment or the non-segmented proximal part, the test piece could not continue further strobilation (A in Fig. 5 and Fig. 6). If the well 


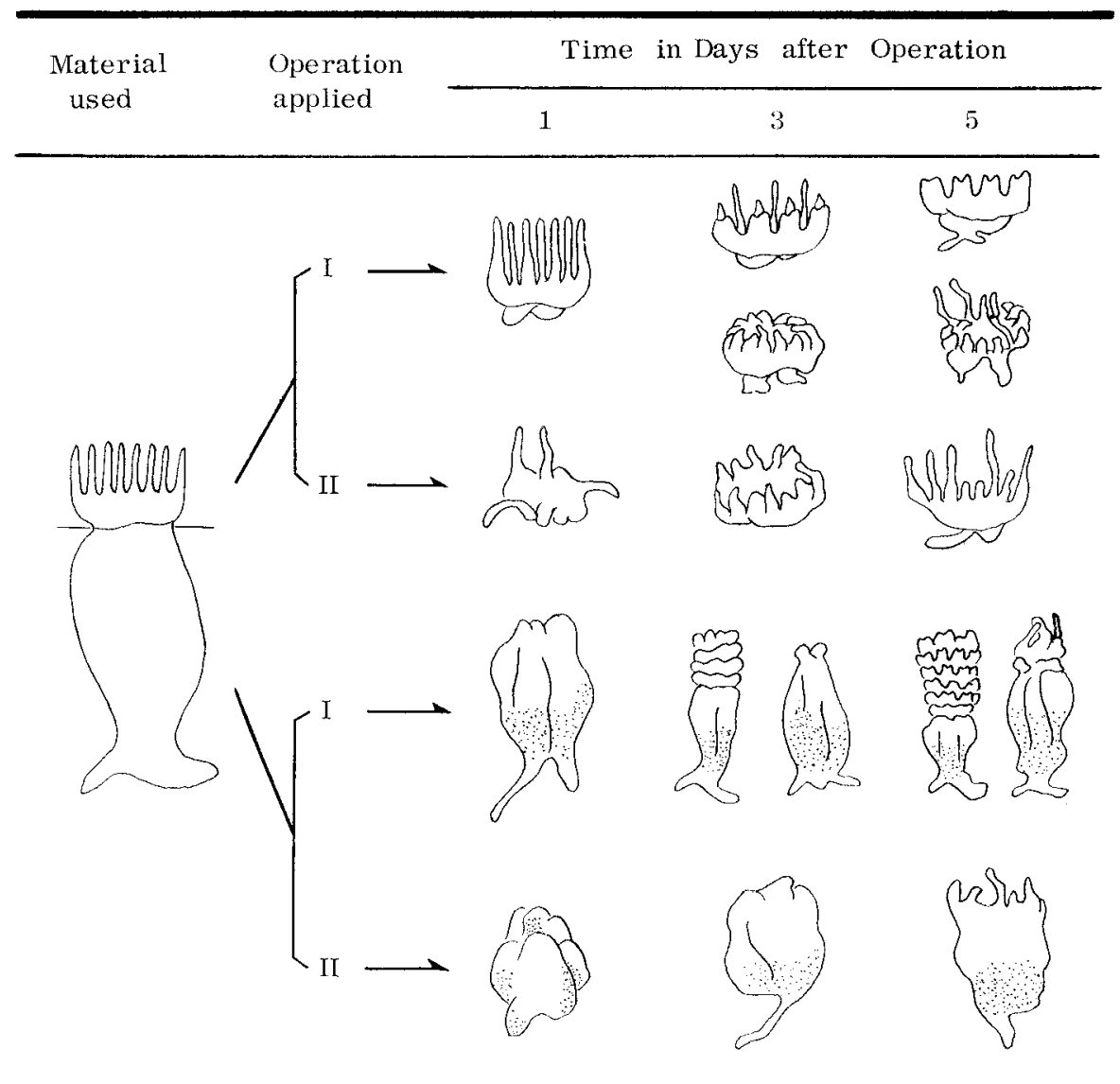

Fig. 4. Subsequent development of two separated piece of strobila obtained from the individual at stage $\mathrm{II}_{1}$.

I, indicates the morphogenesis of the tested pieces which have been cultured after the separation by cutting with a surgical knife. II, is the case of the morphogenesis observed in the tested pieces which have been cultured after the mechanical removal of the endodermal component.

advanced strobilae (Stage $\mathrm{II}_{5}$ ) were used, the segmented part could develop into an ephyra, regardless of the presence or absence of endoderm. The facts seem to suggest that the endoderm may hold a regulating mechanism to lead the ectoderm to continue further strobilation and ephyra formation.

\section{In Vitro Culture of Dissociated Cells taken from Polyp and Strobilae at Different Stages}

The In vitro culture of single cells had been widely carried out by many investigators for studies of tissue organization and differentiation. Using fresh water hydroids, 

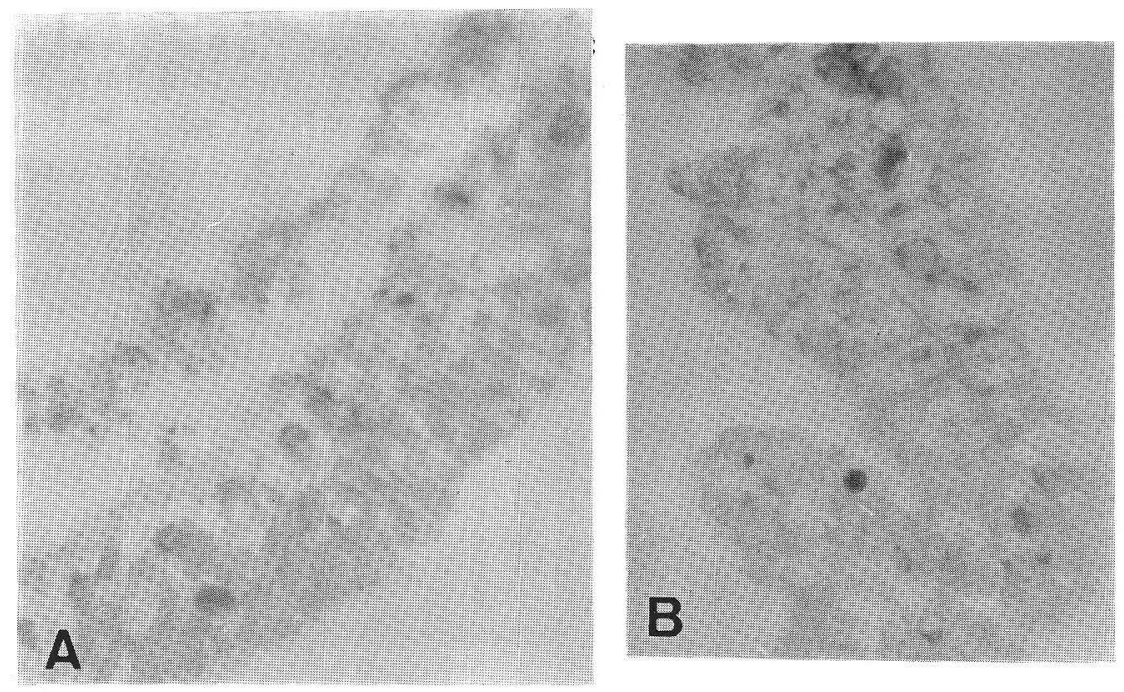

Fig. 5. A shows the case which lost most of the endoderm in the proximal part of the body. Specimen has been obtained from a strobila at stage $\mathrm{II}_{1}$ immediately after the 1 min treatment with the thermomixer. B shows the regeneration of endoderm in the same specimen which has been cultured subsequently for a week.

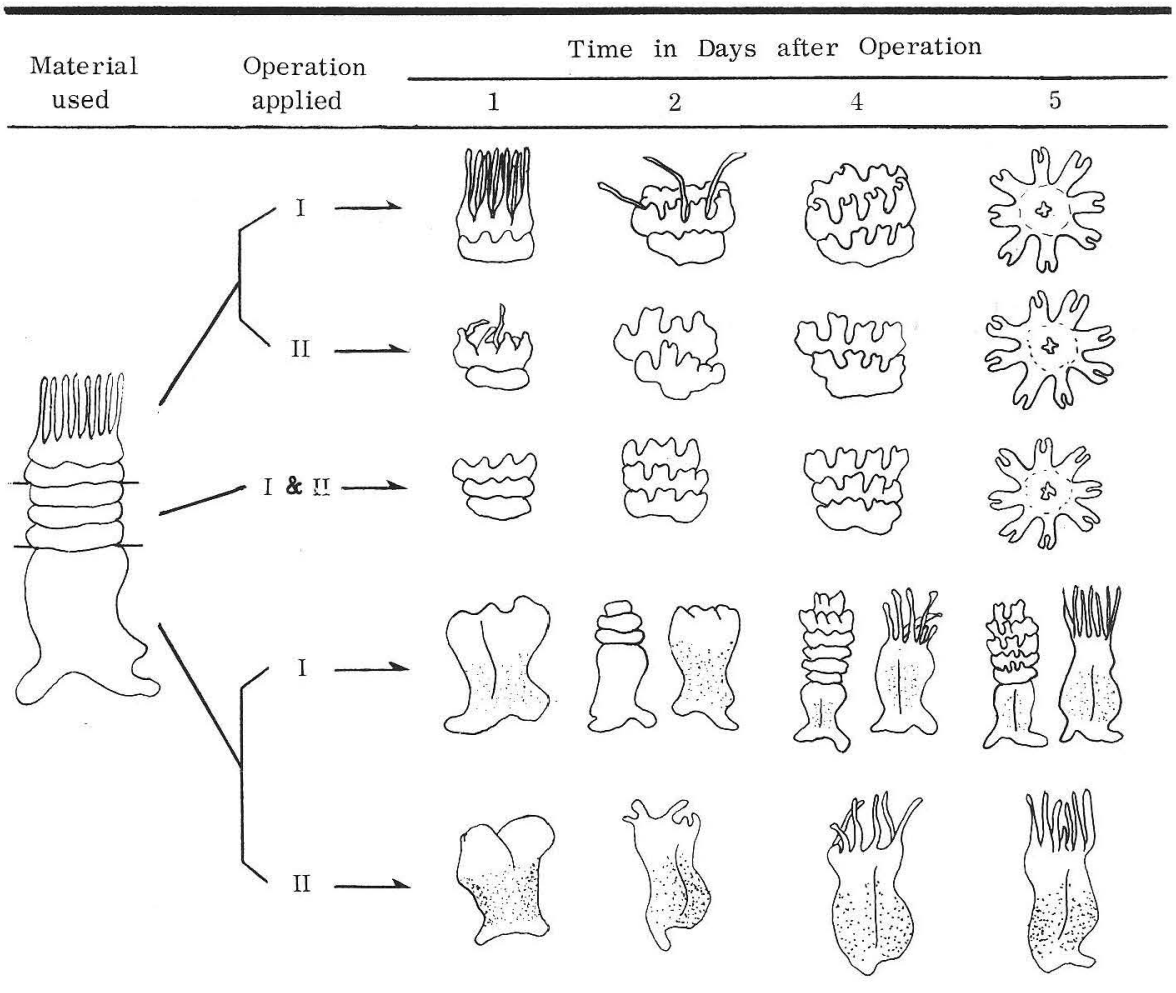

Fig. 6. Subsequent development of different parts of strobila which have been isolated from the individuals at stage $\mathrm{II}_{5}$. I and II mean the same as specified in the explanation of Fig. 4. 
NoDA (1971) obtained a reaggregated form from the dissociated cell aggregate and GIERER et al. (1972) also confirmed the same fact. But, no report is available concerned with the same kind of experiment using marine coelenterates. However, we succeeded in dissociating the Aurelia tissue into single cells by mechanical disruption. The procedure is rather simple. The cell suspension is obtained from the pieces or the whole body of Aurelia by shaking mechanically with the thermomixer for 2-3 min. But, when ephyrae were used as the material, $2 \mathrm{hrs}$ pretreatment with trypsin is required for the successive mechanical disruption. The single cell suspension is dropped into the culture medium consisting of: ASW containing $1 \%$ calf serum, 50 unit per $1 \mathrm{ml}$ of penicillin and $50 \mu \mathrm{g}$ per $1 \mathrm{ml}$ of kanamycin. The suspension was adjusted to the level of $2 \times 10^{5}$ to $3 \times 10^{5}$ cells per $1 \mathrm{ml}$ of the culture medium. Immediately after the dissociation, many cells turned into a spherical shape, then gradually became an

\section{Cells stained with Nile Blue}
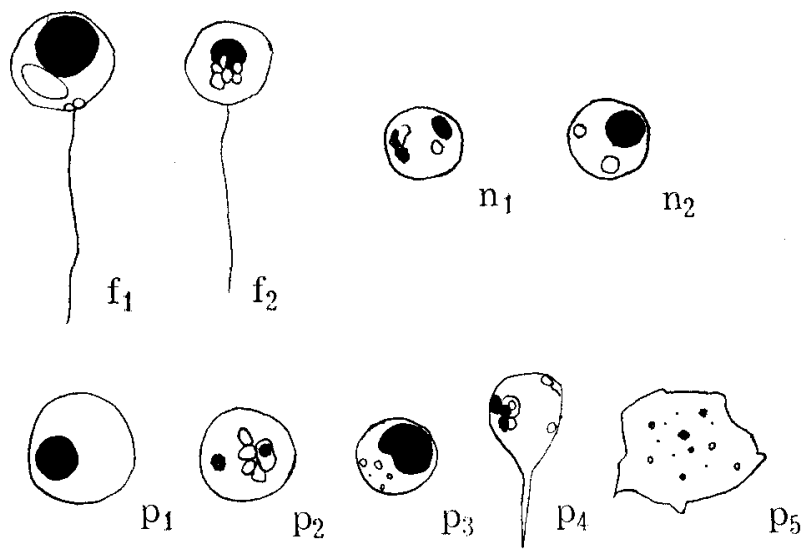

Cells not stained with Nile Blue
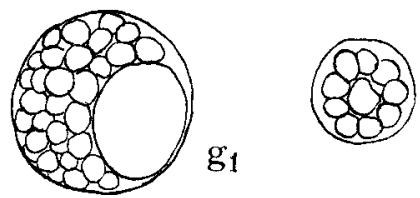

$\mathrm{g}_{2}$

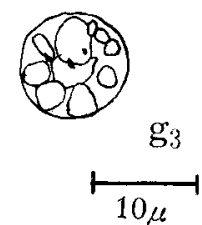

Fig. 7. Various cell-types found in the suspension medium immediately after the cell dissociation procedure. $\mathrm{f}$; flagellated cells. $\mathrm{n}$; normal cells which have no change. $p$; cells transformed into various shapes. Cells belong to these three types contain various cytoplasmic granules, and many of them show a strong affinity to Nile blue. g; cells have no affinity to Nile blue. 
amaeboid shape extending filopodia- or pseudopodia-like processes. The suspended cells can be classified morphologically into four types except the statoliths (Fig. 7). Cell adhesion occurs mainly in the cell group which has affinity with Nile blue ${ }^{1)}$. Cytoplasmic processes hold an important role to initiate cellular contact at first, then proceed cellular adhesion. Fig. 8 demonstrates this process. Major fraction of these non-adhesive cells seems to be derived from the endoderm. Knowing the ectoderm in the polyp is the only structure which can be stained with Nile blue, the cell adhesion occurs mainly in the cell group derived from the ectoderm (A and B in Fig. 9 and Fig. 10). Statoliths do not participate actively in aggregate formation.

Small aggregate can be specified as the primary aggregate. There are definite differences in shape and size of the primary aggregates even at the beginning of aggregation, which can be seen within $3 \mathrm{hrs}$ of incubation. The different types are distinguished and illustrated in Fig. 10. Characteristic behaviour of each type of the aggregates will become more prominent during the following $10 \mathrm{hrs}$ in the culture. The first type is the growth of small primary aggregates through the direct contact with other cells. In this case, no fusion of primary aggregates is observed. This type usually happens in the culture of the polyp or ephyra cells. The second type could be described as follows: some of the peripheral cells of the aggreate become protruded and begin to contact with one or more aggregates, then form a bigger aggregate $(\mathrm{C}$
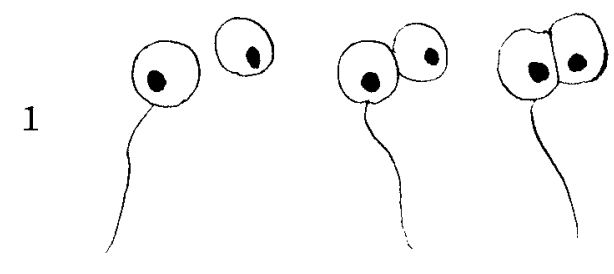

2
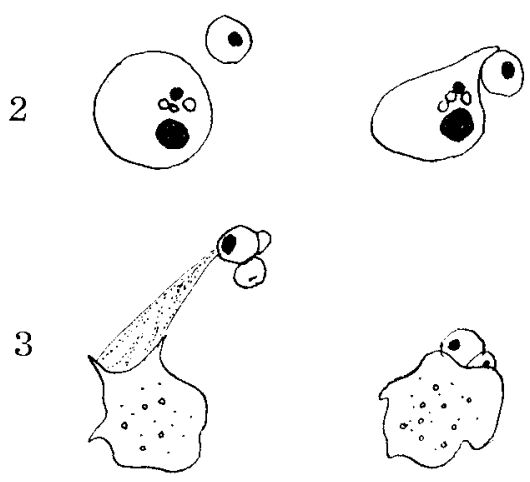

Fig. 8. Various examples of cell-adhesion found after the successful cell dissociation.

1) When the polyps are immersed in the very dilute Nile blue sulfate $\left(8 \times 10^{-4} \%\right)$ for 10 hrs and transferred to ASW, polyps will retain the dye exclusively in the ectoderm. 

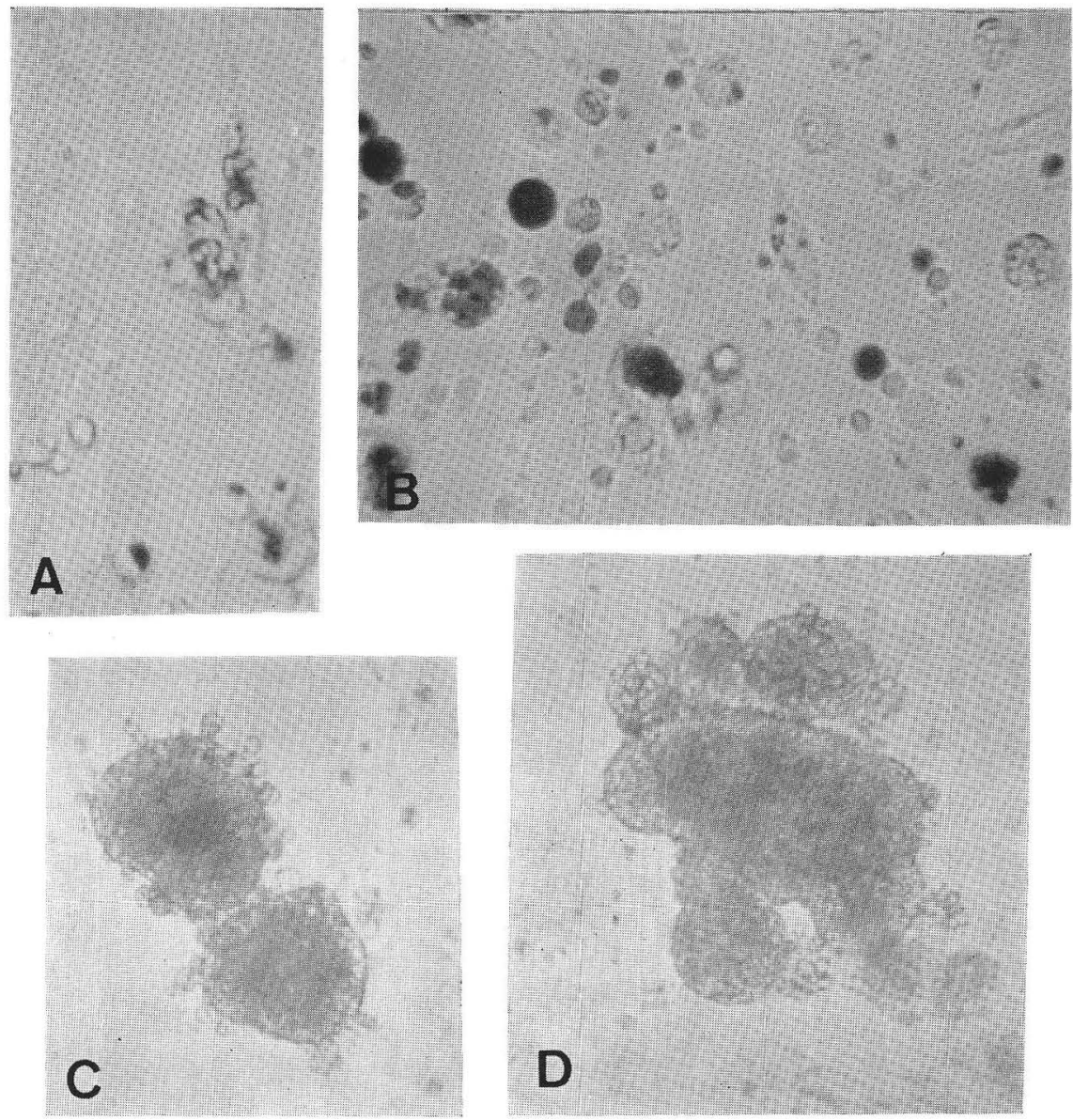

Fig. 9. A and B show the pattern of cell-adhesion in the suspension medium immediately after the cell dissociation. $\mathrm{C}$ and $\mathrm{D}$ show the intercellular contacts between the small primary aggregates which have been formed in one day culture. Test specimens were obtained from the strobila at stage $\mathrm{II}_{3}$.

and D in Fig. 9 and Fig. 10). This type is commonly observable in the cell aggregation from the young strobilae (stage $\mathrm{II}_{1_{-}}$). The third type is the direct growth of an amorphous primary aggregates. This is the case of aggregate formation of cells from the middle strobilae (stage $\mathrm{II}_{5}$-stage $\mathrm{III}_{8}$ ).

In the 3 to 5 day culture, the aggregates from the polyp cells and from the middle strobila-cells start to show characteristic features of a polyp such as the mouth opening and the peduncle formation (Fig. 11 and A,B and D in Fig. 12). We know, on the other hand, that the single or a few number of segments which have been separated from the strobilae (stage $\mathrm{II}_{5}$ ) will develop into ephyra (see p. 184 and Fig. 6 in this report; Kato, Аосні and SAKaguchi, 1973). However, the failure of ephyra formation from the cell aggregate, which is derived from the strobilae, suggests to us that 
primary

aggregation subsequent aggregation

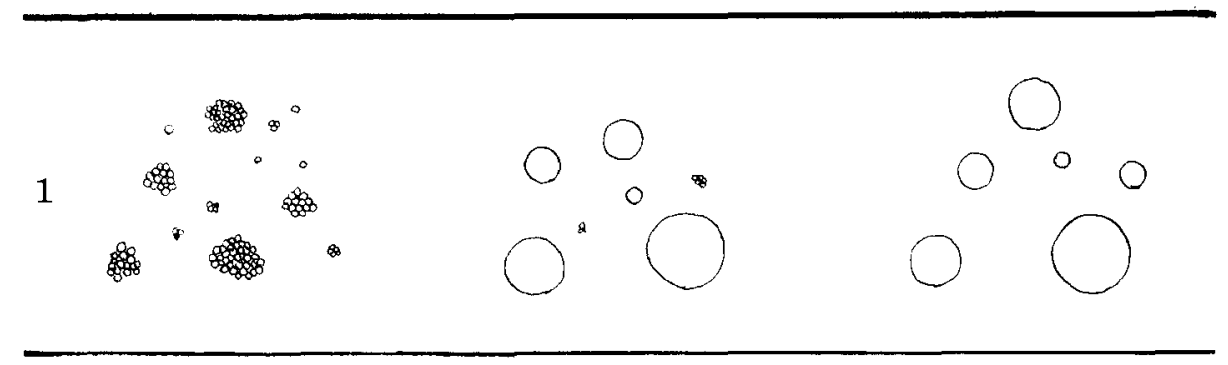

2
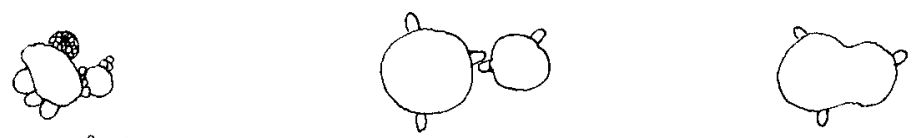

缶

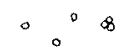

$\circ$

- $\infty$
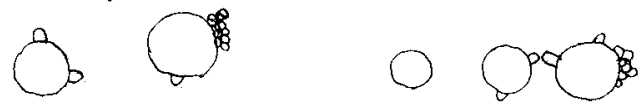

0
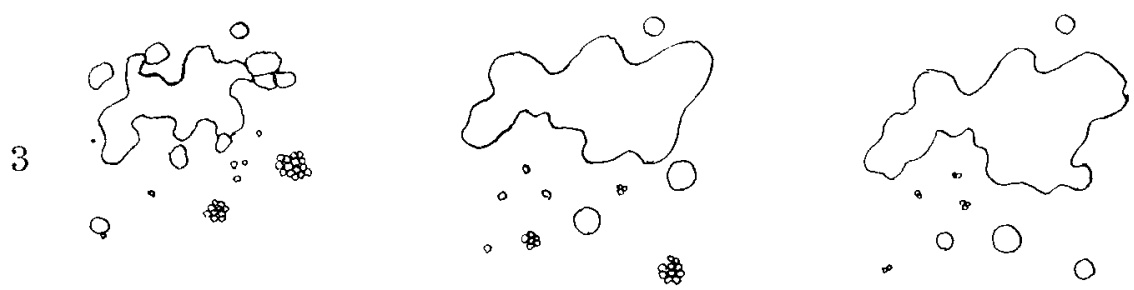

Fig. 10. Various courses of cell aggregates formation (cf. Text p. 188).

the dissociation procedure will damage the regulating factor(s) which might be essential to the cell groups to form the ephyra. When the aggregate is formed by the cells which are taken from the older strobilae (stage V) or the ephyra (stage VI), the aggregate becomes an irregularly shaped ball composed of a single epithelial layer like an outer layer of the normal ephyra (Fig. 11 and E in Fig. 12). Thus, it is plausible that the probable regulating factor which is implicated in the production of ephyra seems to be terminated at Stage IV. At the same time, it should be pointed out that the aggregate derived from the polyp-cells can regulate the formation of polyp holding a single axis, but the aggregate introduced from the strobila usually develops into a multiaxis polyp. In the latter case, many humps of the tentacle primodia occur on the body surface (Fig. 11, and C and D in Fig. 12). Such aggregates become separated eventually into several independent polyps. Strobilation can be considered as the process of establishment of many individuals through segmentation. The formation of the multiaxis polyps in the aggregate could reflect the intrinsic nature of the cells, which appears during the process of the strobilation. Reconstitution of cellular 
Strobilation in Aurelia

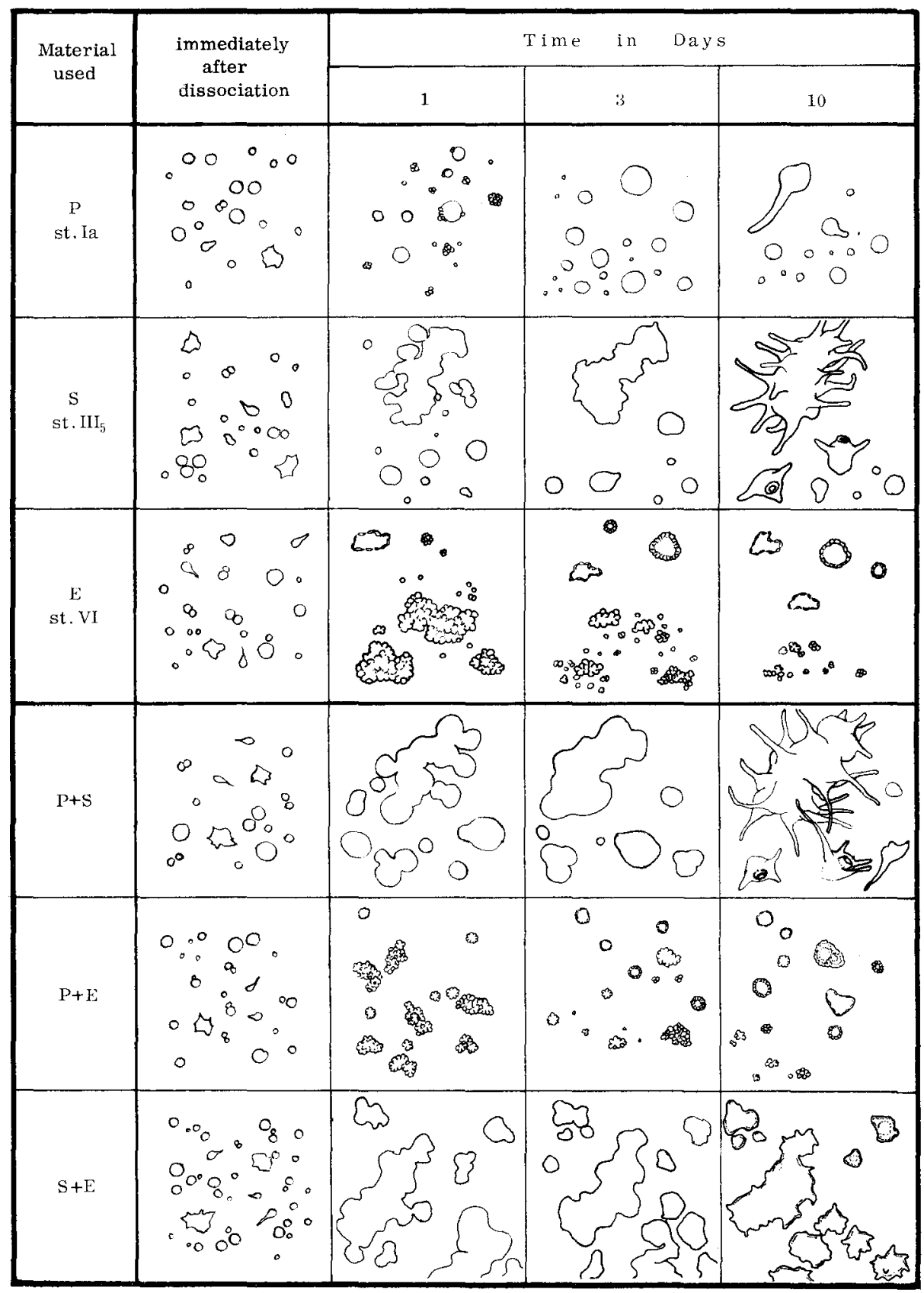

Fig. 11. Aggregate formation and the subsequent morphogenesis observed in the dissociated cell culture derived from the different sources. 

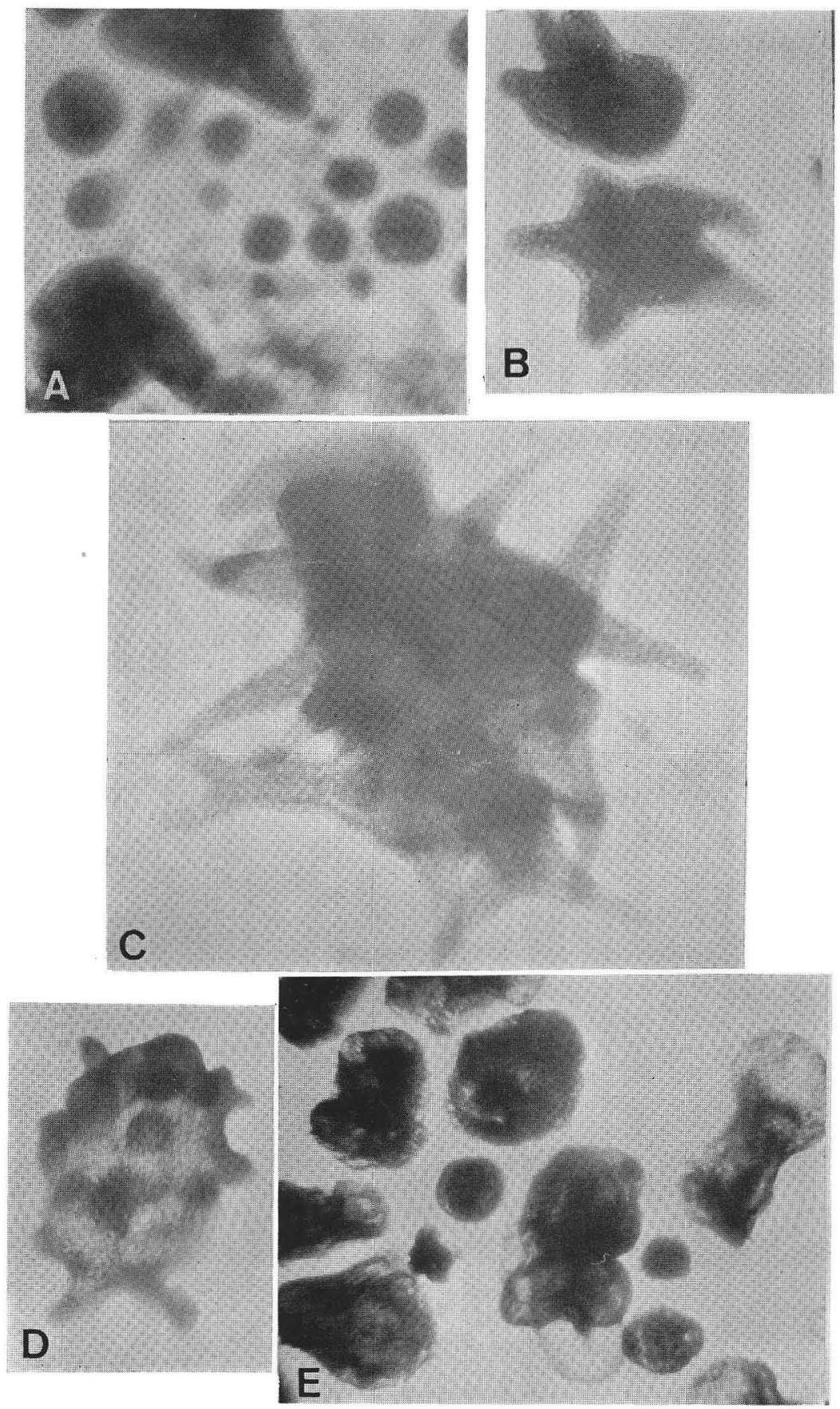

Fig. 12. Morphogenetic change of the aggregates during the period of 10 days culture. A and $\mathbf{B}$ show the aggregates obtained from polyp-cells ( 3 days culture in A, and 5 days culture in B). C and $\mathbf{D}$ are the aggregates from the strobila-cells (10 days culture in $C$, and 5 days culture in $\mathrm{D}$ ). 
architecture, which could correspond to a whole or a part of the polyp, seems to be achieved through intercellular communication. Analytical survey of the various reconstitution of the cell-aggregate in coelenterates will lead us to a better understanding of the mechanism of tissue development.

When the cells obtained from different stages were mixed and introduced to culture condition, the cells behave rather differently from the way described above. Partners for the combination experiment were altered case by case. Polyp cells were mixed with the cells which originated from either the strobila or ephyra, and another was the combination of cells from strobila and ephyra. Through these combination experiments, we found the following results: (1) cells derived from different stages can adhere each other and form an aggregate, and (2) the final status of the aggregate is always the same as the aggregate composed by aged material. It is highly probable that the cells obtained from different stages have an ability to communicate with each other; and furthermore, the cells lead the younger cells to transform into the more advanced structure in the aggregate.

\section{Summary}

1. The morphological details of the process of strobilation in Aurelia are described and discussed.

2. Incorporation of radioactive precursors revealed that the nucleic acids synthesis was reached at maximum at strobila stage.

3. Removal of the endoderm in the polyp or young strobila will not allow them to continue the progress of strobilation. It suggests the existence of the regulation factor in the endoderm, which is necessary for further development.

4. Dissociated cells collected from the various stages show unique cellular behaviour for the aggregate formation.

5. It can be emphasized that the particular and characteristic pattern of strobilation in Aurelia could provide us useful tool to analyse the mechanism of cellular differentiation and tissue organization.

\section{Acknowledgements}

The present authors wish to acknowledge their gratitude to Prof. Takasi TokIOKA of the University of Kyoto who gave us encouragement and opportunity to present this paper on the Symposium. They would like to express their sincere appreciation to Prof. Hidemi SATo, University of Pennsylvania for his criticism and help in preparing the manuscript. Technical assistance was provided by Miss N. IzUHashi and Miss M. KasuYa, to whom the authors wish to express their gratitude.

\section{REFERENCES CITED}

Burnett, A. L., R. Baird, and F. Diehl 1962. Science, 138: 825-826.

Gierer, A., S. Berking, H. Bode, C. N. David, K. Flick, G. Harsmann, H. Schaller, and E. 
TRENKNER 1972. Nature New Biology, 239: 98-101.

Kato, K-I., M. Aochi, and K. Sakagucht 1973. Mem. Osaka Kyo-iku Univ., Ser. III, 22: (in press). Li, Y. F. and H. M. LenhofF 1961. I $n$ : The Biology of Hydra (ed. W. F. Loomis and H. M. LenHoff)

Coral Gables, Florida, University of Miami Press.

NodA, K. 1971. Zool. Mag., Tokyo, 80:99-101.

SPANGenberG, D. B. 1965 . Jour. Exptl. Zool., 160: 1-10.

1968. Oceanogr. Mar. Biol., Ann. Rev., 6: 231-247.

\section{DISCUSSION}

WERNER: Why is the region of highest concentration moving from the upper part to the lower parts in the process of strobilation? Is there a correlation with the regeneration process of the basal part into a new polyp?

Kato: This problem is quite difficult to explain. It is possible to say some physiological difference along the upper to the lower parts seems to be involved in the phenomenon. So far as the incorporation of the radioactive tracers is concerned, we found always much more grains in the upper part than in lower parts. We have some data that regenerative power declines as strobilation proceeds (KaTO et al., 1973).

BRAVERMAN: We have found that blue dyed cells can be destroyed with a ruby raser, this may be of use to you in producing pure cell cultures. Your results are in part reminiscent of studies of DieHL and BoviLLon.. They dissociated and recombined the cell layers of Cordylophora. Whether stolon or polyp formed depended on the proportion of epidermis or gastrodermis that is present.

KATO: Thank you for your valuable comment.

SATo: Would you have any more information concerning the special ectodermal protein which could be synthesized during the strobilation process? Say, for instance, molecular weight, the physico-chemical nature, and so on.

KATO: As I have mentioned, in electrophoretic study of the water soluble protein, we found four protein bands, and one of them would show strong phosphatase activity at both alkaline and acid $\mathrm{pHs}$ when the material was obtained from strobilae (the result was preliminarily reported in Kato and Sengen, 1971, Jap. Jour. Develop. Biol., 25:88-in Japanese). But, we do not have any detailed information at this moment, though further research of this particular protein is in progress. 